\title{
The importance of an early and accurate diagnosis: behavioral variant of frontotemporal dementia (bvFTD). Clinical aspects
}

\author{
Mădălina Ionela Grosu, Anina Rugină, \\ Georgiana-Biatrice Bădii, Ana-Caterina Cristofor
}

Mădălina Ionela Grosu - M.D., Junior Psychiatrist, „Socola Institute of Psychiatry”, Iaşi, Romania

Anina Rugină - M.D., Junior Psychiatrist, „Socola Institute of Psychiatry”, Iaşi, Romania

Georgiana-Biatrice Bădii - M.D., Junior Psychiatrist, „Socola Institute of Psychiatry”, Iaşi, Romania

Ana-Caterina Cristofor - M.D., Ph.D, Lecturer, "Grigore T. Popa" University of Medicine and Pharmacy, Iaşi, Romania

\section{ABSTRACT}

Frontotemporal dementia, a neurodegenerative disorder, is characterized by early onset with an outstanding impact on the patients' life. The most impressive alteration is the occurrence of behavioral manifestation which dominate the clinical picture throughout the entire evolution of the disease. Up to this date, early diagnosis of frontal-temporal dementia remains a challenge especially because it is associatiated with a wide range of symptoms, often perfectly mimicking affective or psychotic disorders. In recent years, positive diagnostic criteria for Frontotemporary Dementia have been nuanced in an attempt to improve the diagnosis process. The evolution of the disease is progressive, with a short survival span and a rapid decline of the patient's state, which represents a challenge for the caretakers in their attempt to provide the necessary care and the permanent supervision required in order to avoid accidents. A common dilema among clinical physicians is related to the prognosis of the illness, but, at present, there is not sufficient data in regard to this matter. The only factor with an impact on the survival prognosis is the presence of language disorders at the first assessment, which associates with a lower survival rate. This paper aims to emphasize once again the significance of a proper diagnosis by presenting a complex case of bvFTD which was quite challenging in terms of differential and positive diagnosis taking into consideration the 
s unusual onset in the form of delusional disorder. Psychotic symptoms such as hallucinations and delusions, are well known to be main symptoms in schizophrenia but are also prominent features in several neurodegenerative diseases (e.g. Alzheimer's disease, dementia with Lewy bodies, psychosis in Parkinson's disease). Therefore, signs of actual bvFTD may often be misinterpreted.

\section{KEY WORDS:}

Frontotemporal dementia, behavioral manifestations.

\section{INTRODUCTION}

Frontotemporal neurocognitive disorder includes patients with onset before 65 years of age. The average survival time after the onset of symptoms is about 6 to 11 years and 3 to 4 years after diagnosis. (1) FTD represents a focal clinical syndrome characterized by profound changes in personality and social conduct being associated with circumscribed degeneration of the prefrontal lobe and anterior portion of the temporal lobes. (2) Early manifestations of FTD are subtle, siding, rarely reported by the patient. The onset is often confused with a "middle age crisis" or other psychiatric conditions, such as depression. However, behavioral manifestations are the most comon presentation symptoms. (3) The Lund and Manchester groups criteria are recommended to be used for the clinical diagnosis of FTD and they consist of: early loss of self-esteem, loss of motivation towards previously appreciated interests and activities, early loss of normal behavior in society, early signs of disinhibition, mental rigidity and inflexibility, impulsivity and attention disorders. Other common characteristics include repetitive and compulsive or even ritualistic behaviors, hyperorality and diet changes, lack of awareness of the disease and lack of criticism of their own actions. Regarding the affective function and its alterations, one may observe: depression, anxiety, fixed and suicidal ideas, delusional behavior (early and transient); hypochondria, bizarre somatic concerns; apathy, lack of empathy and sympathy. (4)
The only factor with an impact on the survival prognosis is the presence of language disorders at the first assessment which associates with a lower survival rate. (5)

An interesting aspect was outlined by some studies conducted in 2012 and 2013 which revealed that a pretty high proportion of patients associate psychotic symptoms. A 2014 review based on 122 publications concluded that the approximate prevalence of psychotic symptoms in FTD is $10 \%$. Moreover, an increased prevalence of psychotic symptoms appears to be associated with specific molecular and genetic subgroups of FTD. Unfortunately, this has not been sufficiently studied so far. (6)

The clinical syndromes of FTD are: the behavioral variant FTD (bvFTD), the progressive aphasias semantic dementia (SD) and progressive non-fluent aphasia (PNFA) (7). A study, which used a cluster analysis to assess anatomical heterogeneity among subjects with bvFTD (8), identified 4 anatomical subtypes which are different by the degree of frontal and temporal atrophy. Two subtypes show massive frontal and two subtypes with predominant temporal lob atrophy. The rate of functional decline is higher in subtypes with frontal atrophy, suggesting that the volume of the frontal lobe could be an useful prognostic tool to predict faster clinical decline. (9) 
Bulletin of Integrative Psychiatry $\bigcirc$ New Series OMarch 2021 Y Year XXVII ONo. 1 (88)/117 s In contemplation of the clinicians need for an new criteria for the diagnosis of bvFTD (tab. diagnostic tool, recent studies have developed 1). (3)

Tab. 1

\begin{tabular}{|c|c|c|c|}
\hline $\begin{array}{l}\text { Criteria for possible } \\
\text { bvFTD } \\
(>=3 \text { criteria) }\end{array}$ & Criteria for probable bvFTD & $\begin{array}{l}\text { Criteria for certain } \\
\text { bvFTD }\end{array}$ & Exclusion criteria \\
\hline $\begin{array}{l}\text { Behavioral } \\
\text { disinhibition }\end{array}$ & Criteria for possible bvFTD & $\begin{array}{l}\text { Criteria for } \\
\text { probable bvFTD }\end{array}$ & $\begin{array}{l}\text { (A) Deficits are } \\
\text { better justified by } \\
\text { other } \\
\text { degenerative } \\
\text { nervous system } \\
\text { diseases or other } \\
\text { medical conditions }\end{array}$ \\
\hline Apathy/inertia & Significant functional decline & $\begin{array}{l}\text { Histopathological } \\
\text { evidence of } \\
\text { frontotemporal } \\
\text { lobar degeneration } \\
\text { by biopsy or } \\
\text { postmortem }\end{array}$ & $\begin{array}{l}\text { (B) Behavioral } \\
\text { disorders are better } \\
\text { explained by a } \\
\text { psychiatric } \\
\text { diagnosis }\end{array}$ \\
\hline $\begin{array}{l}\text { Loss of sympathy / } \\
\text { empathy }\end{array}$ & 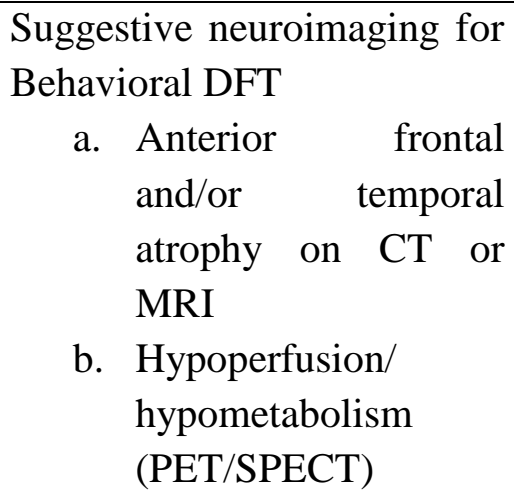 & $\begin{array}{l}\text { The presence of a } \\
\text { known pathogenic } \\
\text { mutation to cause } \\
\text { fronto-temporal } \\
\text { lobar degeneration }\end{array}$ & $\begin{array}{lr}(\mathrm{C}) & \text { Biomarkers } \\
\text { strongly indicate } \\
\text { Alzheimer's disease } \\
\text { or } \\
\text { neurodegenerative } \\
\text { process }\end{array}$ \\
\hline $\begin{array}{l}\text { Perseverative, } \\
\text { stereotype or } \\
\text { compulsive/ritualistic } \\
\text { behavior }\end{array}$ & & & $\begin{array}{l}\text { Criteria A and B } \\
\text { must be negative } \\
\text { for any diagnosis of } \\
\text { behavioural FTD } \\
\text { Criterion C may be } \\
\text { positive for possible } \\
\text { behavioral FTD, but } \\
\text { must be negative } \\
\text { for probable } \\
\text { behavioural FTD }\end{array}$ \\
\hline \multicolumn{4}{|l|}{$\begin{array}{l}\text { hyperorality and diet } \\
\text { changes }\end{array}$} \\
\hline $\begin{array}{lr}\text { Significant } & \text { decline in } \\
\text { social } & \text { cognitive } \\
\text { function } & \text { and/or } \\
\text { execution functions }\end{array}$ & & & \\
\hline
\end{tabular}


CASE PRESENTATION

A 60-year-old female patient from the urban area is brought in the emergency room by police being accompanied by her daughter. The patient was taken in custody because a saleswoman called 112 and reported that the patient was trying to stuff food into her bag avoiding to pay for it. Her daughter, with whom the patient lives, declares that her mother leaves home frequently and she even leaves the door unlocked and open. This kind of behavior is typical and frequent for dromomania. Furthermore, the daughter states that her mother used to work abroad, in Italy, and that she returned in 2017 being a little bit different and acting strange. Her behaviour was accounted for stress. In the emergency room, the patient presents a symptomatology manifested by: psycho-motor agitation, behavioral manifestations, physical and verbal hetero-aggressiveness, spatial temporal disorientation and also auto and allopsychic disorientation, hyperesthesia, incoherent speech.

\section{MEDICAL HISTORY}

The patient is in the records of the Socola Iasi Institute of Psychiatry with 2 previous hospitalizations. The first hospitalization was in 2018, at the age of 58, within the context of a psychiatric emergency for a symptomatology objectified by: unsystematized delusion, disorganized thinking, dysphoric mood, low frustration tolerance, persecutory delusions, impaired attention. The psychological evaluation highlighted: decreased cognitive functions, spatial temporal disorientation, delusional tendencies, irritability, irascibility. The cranio-cerebral CT scan report was within normal limits. The patient was diagnosed with "Persistent Delusional Disorder".

The patient returned in 2019, also via psychiatric emergency presenting symptoms such as: marked psycho-motor agitation, impulsive behaviour, hyperesthesia, decreased global cognitive functions, spontaneous and voluntary hypoprosexia, fixation and evocation hypomnesia, bradypsychia, temporo-spatial disorientation and incoherent speech. The psychological examination highlighted: uncooperative patient, behavioral manifestations, incoherent speech, severe cognitive dysfunction, auto and allopsychic disorientation, impared judgment, episodes of confusion with dromomania. Furthermore, inability to self-conduct and self-care led to total socio-familial dependence. Craniocerebral CT exam revealed frontotemporal cerebral atrophy. Diagnosis at discharge were: "1. Frontotemporal Dementia- severe form $($ REISBERG $=6 \mathrm{P}) ; 2$. Need for continuous supervision."

\section{PSYCHIATRIC EXAMINATION}

During the psychiatric examination, the patient had an uncooperative attitude. The outfit is untidy and body hygiene is poor. There is a global cognitive decline, irritability, irascibility, voluntary and spontaneous hypoprosexia, difficulty concentrating, difficulty switching focus, marked distractibility and fixation and evocation hypomnesia. Cognitive dissonance with bradypsychia. Simple language, verbal stereotypes, inadequate answers were also present. The eating instinct is diminished, sometimes with food refusal; the selfpreservation instinct is low being unable to recognize dangerous situations the gregarious instinct - tendency to socially isolate oneself. Volitionally, the patient has hypobulia for daily activities. Motor behaviors includes bradykinesia with inability to self-conduct and self-care. The impulses escape from volitional control. Additionally, the patient displays episodic verbal and physical heteroaggressive behavior and aggression towards the medical staff. 
Bulletin of Integrative Psychiatry O New Series OMarch 2021 ○ Year XXVII ONo. 1 (88)/119

Paraclinical investigations: the native cranio-cerebral CT objectifies a slightly more accentuated frontotemporal cerebral atrophy (compared to the previous examination from 2019) with ventricular and subarachnoidal space enlargement.

\section{POSITIVE DIAGNOSIS}

The patient is likely to suffer of probable Frontotemporal Dementia (according to the criteria of the Lund and Machester groups). The onset of the patient's disease at the age of 59 is a criterion that supports this diagnosis as well as the increase of cerebral atrophy in one year which is a diagnostic marker for FTD. Besides, the patient presents behavioral manifestations and affective disorders that are typical for bvFTD.

\section{DIFFERENTIAL DIAGNOSIS}

Dementia in Alzheimer's Disease - the onset of the disease is insidious with a slow evolution, symptomatology usually occurs in the eighth and ninth decades of life. Behavioral changes occur late in the evolution of the disorder.

Dementia with Lewy-body - the patient does not show features that suggest the presence of lewy bodies.

Dementia in Parkinson's disease - there is no personal pathological history of Parkinson's disease.

Vascular dementia- can not be considered because there is no cerebrovascular event temporally related to the onset of cognitive impairment in the patient's history.

Other neurological disorders such as Progressive supranuclear paralysis and Corticobasal degeneration are ruled out.
TREATMENT

During hospitalization the patient underwent specialized treatment with: Memantine 20 $\mathrm{mg} /$ day, Carbamazepine $400 \mathrm{mg} /$ day, Lorazepam 3mg/day, Trazodone $150 \mathrm{mg} /$ day, Risperidone solution $4 \mathrm{ml} /$ day, as well as Diazepam f. 1f im in case of psychomotor agitation. On discharge it was recommended to continue treatment with Memantine 20 $\mathrm{mg} /$ day, Carbamazepine $400 \mathrm{mg} /$ day, Bromazepam 3mg/day, Trazodone 150 $\mathrm{mg} /$ day and Risperidone solution $4 \mathrm{ml} /$ day.

Since acetylcholinesterase inhibitors, used in Alzheimer's, have not proven their effectiveness in frontotemporal dementia, with studies showing that they can exacerbate behavioural symptoms (3), memantine, an NMDA receptor antagonist, has been chosen.

Serotonin antidepressants have been reported to decrease behavioural manifestation (especially repetitive ones), disinhibition, apathy, inappropriate sexual behaviors and hyperorality. No beneficial effects on cognitive and functional abilities have been proven. Lebert and Pasquier evaluated 14 patients with frontotemporal dementia treated with trazodone, an atypical serotonin agent which increases extracellular levels of 5 hydroxytriptamine in the frontal cortex. After 4 weeks of treatment, relief of behavioural symptoms such as anxiety, irritability, aggression was observed, after 6 weeks relief of depression, disinhibition and motor symptoms was noticeable. (10)

Evidence of the use of antipsychotics in treatment of FTD is limited because of the extrapyramidal side effects. However, in patients with severe behavioral disorders, second- or third-generation ones are preferred. The risk-benefit ratio should be balanced, given the risk of heart complications and sudden death. (11) In the current case, 
s. risperidone was opted for administration Antiepileptics with thymostabilizing effects, which succeeded in attenuating the behavioral such as carbamazepine and valproic acid, symptomatology. have been reported to relieve behavioural symptoms (Class IV). (11)

\section{DISCUSSION}

The case presented outlines the difficulty of establishing a correct diagnosis. It should be noted that in this particular case, the onset took place in the form of delusional symptomatology. A retrospective study from 2011 shows how more than half of people with this type of dementia are initially diagnosed with other psychiatric pathologies. (12) As the intial symptoms were quite uncommon for FTD, the family members had difficulties in accepting the diagnosis. Once the disease progressed it became even harder for them to deal with it. The education of the family (the caregivers) regarding the diagnosis of bvFTD was required. The caregiver burden is a real problem which has tremendous consequences not only for the patient and his/hers family but also for the society. As the population of the plant ages, the number of patients with dementia is increasing and it becomes a public health crisis. (13) Numerous studies were conducted in order to evaluate the mental health of caregiver for dementia and the results were alarming. Not rarely the caregivers become second patients as they try to manage their personal life, career and the new responsibility: caring for a beloved person with dementia (14) In the case presented, the caregivers were explained the complications, the evolution and the outcome of this pathology as the main goal is to improve the patient's quality of life but to also make their burden easier on the process. Unfortunately, the patient does not benefit from adequate family support which is an unfavorable prognostic factor. Permanent supervision at home is necessary so as to avoid accidents and to make sure that the medicines are correctly administrated. Moreover, it is highly recommended to establish a routine in order to create a psycho-protective climate in the socio-familial environment and to avoid psychotraumatic conflict situations that could endanger the life of the patient and of those around her. This recommendation brings up another issue: the institutionalization of dementia patients, a long disputed subject which proved to have both beneficial effects and sometimes less positives ones. (15) Discouragingly, in Iasi, there are not many options to choose from when it comes to the institutionalization of the patient. Thus in the case presented, the patient remains in the care of the daughter. An intriguing phenomenon that caught the psychiatrists' attention in the last years and may be applicable to the case presented is called Italy Syndrome. Italy syndrome is a form of social depression that occurs primarily in people who do not have a medical background, but who care for a long time people with severe illnesses. From the patient's personal history we learn that she had been at work in Italy for 13 years, between 2004 and 2017 as an elderly carer. There are multiple possible psychotraumatizing factors in the case such as: being away from home for a long period of time in an environment which she felt as being foreign and/or hostile; the extended schedule without sufficient hours and days of rest; the precarious mental state of the person she was caring for; the fact that she did not know the language well enough and she could not easily communicate with people around her. However, further research is needed as more and more persons who work abroad as caregivers manifest features of this syndrome. 
The case presented stresses not only the importance of an accurate and proper diagnosis but also draws attention to the problematic of the caregiver burden and of the institualization of the patients with dementia. In addition, it tried to raise awareness about the new phenomenon called Italy syndrome.

\section{ACKNOWLEDGEMENTS AND DISCLOSURES}

The authors state that there are no declared conflicts of interest regarding this paper.

\section{REFERENCES}

1. American Psychiatric Association. Diagnostic and Statistical Manual of Mental Disorders DSM-5. 5th ed. 1. American Psychiatric Association. Diagnostic and Statistical Manual of Mental Disorders DSM-5. 5th ed. Washington, DC: American Psychiatric Association; 2013

2. David Neary; Julie Snowden; David Mann (2005). Frontotemporal dementia., 4(11), 771-780. doi:10.1016/s14744422(05)70223-4

3. Seeley, W.W.(2019). Behavioral Variant Frontotemporal Dementia. CONTINUUM: Lifelong Learning in Neurology, 25(1), 76-100. doi: 10.1212/con.0000000000000698

4. Journal of Neurology, Neurosurgery and Psychiatry. 1994. PMID: 8163988 Clinical and neuropathological criteria for frontotemporal dementia. The Lund and Manchester Groups.

5. Garcin, B., Lillo, P., Hornberger, M., Piguet, O., Dawson, K., Nestor, P. J., Hodges, J. R. (2009). Determinants of survival in behavioral variant frontotemporal dementia. Neurology, 73(20), 16561661. doi:10.1212/wnl.0b013e3181c1dee7

6. Landqvist Waldö, Maria; Gustafson, Lars; Passant, Ulla; Englund, Elisabet (2015). Psychotic symptoms in frontotemporal dementia: a diagnostic dilemma? International Psychogeriatrics, 27(4), 531539. doi:10.1017/s1041610214002580

7. Shinagawa, Shunichiro (2015). Rosenberg's Molecular and Genetic Basis of Neurological and Psychiatric Disease Frontotemporal Dementia. 779-791. doi:10.1016/B978-0-12-410529-4.00069-3

8. Whitwell JL, Przybelski SA, Weigand SD, et al. Distinct anatomical subtypes of the behavioural variant of frontotemporal dementia: a cluster analysis study. Brain. 2009; 132:2932-2946.

9. Josephs KA Jr. Whitwell JL, Weigand SD, et al. Predicting functional decline in behavioural variant frontotemporal dementia. Brain. 2011; 134:432-448.

10. Natalie D Weder; Rehan Aziz; Kirsten Wilkins; Rajesh R Tampi (2007). Frontotemporal Dementias: A Review. , 6(1), 15-0. doi:10.1186/1744-859x-6-15

11. Tsai, Richard M.; Boxer, Adam L. (2014). Treatment of Frontotemporal Dementia. Current Treatment Options in Neurology, 16(11), 319-. doi:10.1007/s11940-014-0319-0

12. Woolley, J.D., Khan, B.K., Murthy, N.K., Miller, B.L., Rankin, K.P. (2011). The Diagnostic Challenge of Psychiatric Symptoms in Neurodegenerative Disease. The Journal of Clinical Psychiatry, 72(02), 126-133. doi: $10.4088 /$ jcp.10m06382oli

13. https://www.ncbi.nlm.nih.gov/pmc/articles/PMC5550537/

14. Brodaty H, Donkin M. Family caregivers of people with dementia. Dialogues Clin Neurosci. 2009;11(2):217-28. doi: 10.31887/DCNS.2009.11.2/hbrodaty. PMID: 19585957; PMCID: PMC3181916.

15. Eska K, Graessel E, Donath C, Schwarzkopf L, Lauterberg J, Holle R. Predictors of institutionalization of dementia patients in mild and moderate stages: a 4-year prospective analysis. Dement Geriatr Cogn Dis Extra. 2013 Nov 1;3(1):426-45.

\section{Correspondence:}

Anina Rugină,

M.D., Junior Psychiatrist, „Socola Institute of Psychiatry”, 36 Bucium Street, Iasi, Romania, anina.gavrilita@gmail.com 